\title{
4 次元陰関数を用いた時系列連続断層画像の形状表現
}

渡部 広志 Hiroshi WATABE 金井 崇 Takashi KANAI
近藤 邦雄 Kunio KONDO

道川隆士 Takashi MICHIKAWA
大竹豊 Yutaka OHTAKE
概要: 連続断層画像は近年の測定技術の進歩により 様々な場面で取得されるようになった。連続断層画像 の例として医療の現場で使われる MRIやCT，工業製 品の開発, 改良のための CT の利用などが挙げられる. こういった連続断層画像の応用技術の可能性の一つと して，動きを持つ形状の可視化がある。例えば物体の 時間的な形状変化を表寸，時系列をもつた連続断層画 像に対するモデリングと可視化といったものである。 本論文では，4次元陰関数を用いた時系列を持つ連続 断層画像のモデリングおよび可視化手法を提案する。 提案手法は， 2 值化した連続断層画像に対して，SLIM 曲面と呼ばれる陰関数曲面を当てはめることで 4 次元 陰関数曲面モデルを生成する，提案手法により，任意 の時間における 3 次元形状が簡単に計算できる 4 次元 陰関数曲面モデルが得られる。そして本手法を用いた 実験により動きを持つ形状の可視化に対寸る有用性を 示した。

キーワード：形状処理／陰関数曲面／位相変化

\section{1.はじめに}

近年, 測定機器の発達により，生物細胞などの非常に 小さい対象の振る舞いを 3 次元でかつ時系列に記録し た 4 次元の連続断層画像が取得できるようになった。こ れらを用いて，今まで未知であった細胞の振る舞いに関 する性質など，新しい知見が得られる可能性がある。し かし，得られたデー夕は，2次元画像の集合であり，そ こから性質を把握するのは難しい, 得られた画像を, ア ニメーションなどを用いて可視化できれば, 細胞の振る 舞いを俯瞰的に観察することができ，新たな知見の発見 に役立つ可能性がある. 3 次元画像を用いた形状モデリ ングは、これまでにも医療分野，工業分野において活発 に行われている。本研究の対象亡なる動的な生物細胞画 像は, これらと比較して以下の特徽を持つ。

- 画像に動きが存在する

・細胞分裂時において位相の変化が発生する

・断層画像に存在するノイズの量が多い

-工業製品之異なり, エッジのない, 滑らかな曲面 で構成される

以上の要件を満たすモデリング手法はほとんど存在し ない、モデリングの際にはこれらの特徴を考慮し，かつ さまざまな可視化に適応しうるデータ形式のモデルを 生成することが必要とされる。

本研究では，時系列を持つ連続 2 值画像を対象上し た，4次元モデリング手法を提案する。 4 次元モデリン
グは，3 次元空間に時間軸の值を考慮した嵏間に陰関数 曲面老当てはめる方法で行う。本手法は，一定の時間間 隔でサンブリングされた連続断層画像に対し 2 值化を 施した時系列連続 2 值画像を入力と寸る. 2 值画像に対 して，位相の変化するデータとの親和性が高い陰関数を 直接当てはめることで 4 次元モデリングを行う，陰関数 には,コンパクトな陰関数曲面として知られるSLIM 曲 面を 4 次元に拡張して用いた。本手法で得られたモデル の可視化は，パラメータとして時刻を与えることで容易 に行われる，本論文では，いくつかの例題に提案手法を 適用し，その有用性㧍よび特徽について考察を行った。

以下， 2 節では，本研究で用いる陰関数に関連する従 来研究, 3 節では, 3 次元形状を現寸連続断層画像に対 寸る陰関数当てはめ, および時系列データへの拡張につ いて述べる．4節では，提案手法を用いた実験例と，実 験例の考察を述べる。最後に 5 節で，本論文のまとめと 今後の展望について述べる.

\section{2. 陰関数に関する従来手法}

本節では，まず，本吥究で用いる陰関数表現について 述べる. 次に陰関数を用いた様々な形状モデリング手法 の特徵とSLIM 曲面モデリング，そしてそれらのモデル の可視化手法について述べる.

\section{1. 陰関数による形状表現}

$f(x, y)=0$ という記述で表現される関数を陰関数と いう。陰関数は，物体の表面からの距離によるスカラー 場を形成することで，物休の内外の判別が可能なモデル を表現する。陰関数 $f(x, y)=0$ では各点 $\left(x_{i}, y_{i}\right)$ に対 ᄂ $f\left(x_{i}, y_{i}\right)=0$ を物体の表面, $f\left(x_{i}, y_{i}\right)<0$ を物休の 内部, $f\left(x_{i}, y_{i}\right)>0$ 老物体の外部と定義することでソ リッド (固体) 表現を行う。図 1 に, 物体の表面からの 距離によるスカラー場の例を示寸。

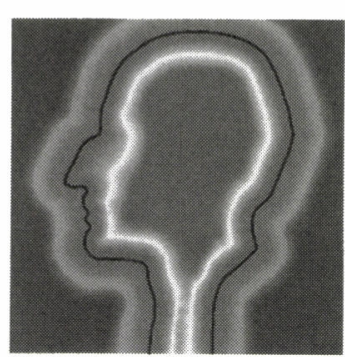

図 1 物体の表面からの距離を表すスカラ一場の例 


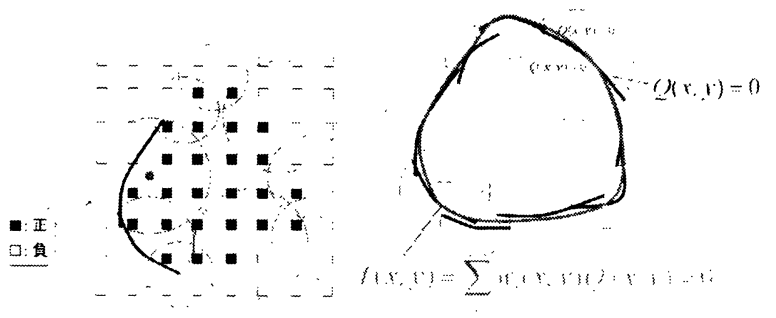

図 2 SLIM 曲面モデリングを用いた 2 次元データに 対する陰関数曲面の当てはめ

\section{2. 陰関数を用いた形状モデリング}

陰関数 $(f(x, y)=0)$ は以下の特徵を持つ.

- 物休の内外の識別が可能

・集合演算による複数物休の衝突，分離など位相が 変化する現象を容易に表現可能

3 次元上の離散データを元に陰関数曲面を当てはめ形状 を表現する手法はいくつも存在するが，本䂨究ではそ の巾の一手法である Sparse Low-degree Implicit(SLIM) 曲面モデリング [1] を元に, 4 次元の陰関数曲面の当ては めを行う．SLIM 曲面モデリングは大竹らによって提案 された Multi-level Partition of Unity Implicits(MPU) によるモデリング [2] の改良手法である.

SLIM 曲面モデリングでは物体の表面 (前景と背景の 境界) 上にのみ配置し，球の内部に陰関数により曲面を 当てはめて形状を表現している(図 2)．SLIM 曲面は以 下のような特徵を持つ.

・物体巾の全ての点を用いて形状を表現する MPU に比ベデータが軽量

・各近似関数ごとに異なる大きさの球を用いること により，精度を保ったデータ量の軽量化が可能

・滑らかな表面

- 低次多項式近似で，モデルの表面の曲率や法線を 簡単かつ高品質に導出

- 従来手法 [2].[3] のように内外判定において，大規模 連立方程式を解く必要がないため高速に計算可能

・GPUを用いた高速レンダリングが可能 [4]

SLIM 曲面は, 物体の表面上の点のみを候補に陰関数曲 面の当てはめを行う．物体中のすべての点を候補にして 曲面の当てはめをする手法に比へ，軽量なデータでモデ ルが表現できる，関数を当てはめるための候補となる 点が物体中の全点を候補とする場合に比べ少ないため, 当てはめに用いる時間の短縮も期待できる．また，近似 がしや寸い形状であればより大きい球を当てはめ，近似 が困難な形状であればより小さい球をあてはめて関数 の影響範囲を定めることで，近似関数の精度を保ちなが ら，無駄の少ないデータで形状の表現をすることが可能
である.ささら，曲面の近似に用いる関数に低次多項式 を用い，複数の近似関数が交わる領域では関数のブレン ディングを利用寸るためモデルの表面を滑らかに表現で きる.関数による形状表現の為，モデルの表面の曲率や 法線が容易に高品質なものを導ける，曲率はNPR（陰 付けや特徵抽出），法線はレンダリングなどさまざまな モデルの表現に用いられ，これらの見積もりが容易であ ることは可視化に適したモデルであるといえる．SLIM はRBFに比べ描画力において劣るとされるものの，計 算量の少なさが利点とされるモデリングであり，大規模 な入力データへの対応が可能である.

\section{3. 可視化手法}

陰関数の可視化には，大別して二種の手法が用いられ る.一つは, レイキャスティング (Ray Casting) 法やレ イトレーシング (Ray Tracing) 法などの画素毎に視線か ら光線を飛ばし，物体との交点を求めることで陰関数曲 面を直接描画寸る手法である.

もう一つは, マーチングキューブ (Marching Cube) 法 [5] に代表される等值面生成手法を用いてポリゴンを生 成し，それを表示寸る手法である。マーチングキューブ 法は抽出点が格子状の点を利用するためシャープなエッ ジの描画力が弱いなどの問題点がある。拡張マーチン グキューブ (Extend Marching Cube) 法 [6] は，シャー プなエッジの表現を出来るように拡張された手法であ るが，処理の前提条件としてシャープなエッジの箇所の 情報を得る必要があった。デュアルカンタリング (Dual Contouring) 法 ${ }^{[7]}$ は前処理の必要なくマーチングキュー ブ法において困難であったシャープなエッジの表現を可 能としている.

\section{3. 陰関数曲面の当てはめ}

本節では，連続断層画像で表された 3 次元の形状及び 時系列連続断層画像で表された 4 次元の形状に対寸る 陰関数曲面モデルの生成と可視化について述べる.

\section{1 . 提案手法の概要}

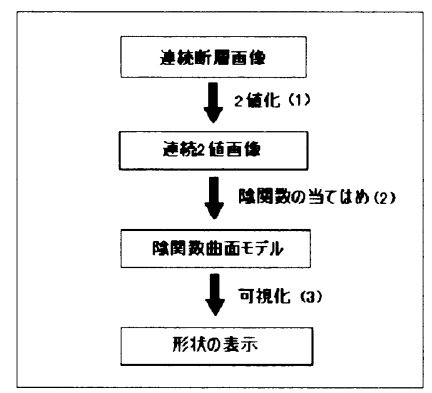

\section{図 3 陰関数曲面当てはめの処理概要}

図 3 に陰関数曲面当てはめの処理概要を示寸. 3 次元 の陰関数曲面モデル生成の際には, 入力に連続断層画像 
を用いる．まず，連続断層画像を 2 值化により連続 2 值 画像に変換する必要がある（図 $3(1))$ ．入力画像巾の ノイズは 2 值化処理により除去する．本研究では，簡単 のために連続断層画像の 2 值化はすでに行われているも のとする. 次に, 連続 2 值画像に対し, SLIM 曲面の生 成アルゴリズムにより陰関数曲面モデルを生成する (図 $3(2))$. 処理 (2) の詳細については 3．2., 3. 3. 節にて 述べる. 最後に, 処理 (2) で生成されたモデルを可視化 する (図 $3(3)$ ).

4 次元の陰関数曲面モデルの生成の際には, 入力デー タとして一定の時間間隔でサンプリングされた, 時系列 連続断層画像を用いる。 まず，それぞれの時間における 連続断層画像を, 2 值化により連続 2 值画像に変換する ことで時系列連続 2 值画像を生成する. 次に，時系列連 続 2 值画像に対して 4 次元の陰関数曲面を当てはめる ことで，離散時間値間の物体の挙動を補完する, 動的な 形状に対するモデルを構筑する，最後に，生成したモデ ルに対しさまざまなアプローチでもって物体の変化や動 きがわかる可視化を行う。

\section{2. 陰関数の当てはめ}

本小節では, 曲面近似の際に用いる陰関数の導出手法 について述べる.

SLIM 曲面において, 一つの関数の影響する領域は, 関数当てはめの巾心点 $p$ から半径 $r$ の球の範囲である. 前景と背景の境界上に複数の球をばら撒き，それらの 内部における形状を，それぞれ曲面で近似する（図 2）。 3 次元の形状に対する関数当てはめでは, 求める関数の 近似を, 以下の 3 変数 2 次多項式を用いて表す.

$$
\begin{aligned}
Q(x, y, z) & =A x^{2}+B y^{2}+C z^{2} \\
& +D x y+E y z+F z x \\
& +G x+H y+I z+J
\end{aligned}
$$

球内の点 $\mathbf{x}_{\mathbf{i}}$ について, 物体の内部の点であれば $Q\left(\mathbf{x}_{\mathbf{i}}\right)=$ $r$, 物体の外部の点であれば $Q\left(\mathbf{x}_{\mathbf{i}}\right)=-r$ とする. 球の内 部の全点に対してこの評価を行うと, 係数 $A, B, C, D, E$, $F, G, H, I, J$ に関する多項式が得られる. それをまとめ ることで得られる連立方程式を解くことで, 係数の值が 得られる.

4 次元の形状に対する関数当てはめにおいては, SLIM 曲面における関数の影響領域である球として, $x, y, z, t$ 軸方向に半径 $r$ の範囲を被覆する 4 次元の球を用いる. 4 次元の形状に対する関数当てはめでは, 求める関数の 近似を, 以下の 4 変数 2 次多項式を用いて表す.

$$
\begin{array}{r}
Q(x, y, z, t)=A x^{2}+B y^{2}+C z^{2}+D t^{2} \\
+E x y+F x z+G x t+H y z+I y t+J z t \\
+K x+L y+M z+N t+O
\end{array}
$$

3 次元の形状に対する関数当てはめと同様の手法で式 2
の係数の值を求める.

当てはめた曲面の評価には，関数の影響範囲である球 の内部において内外のずれが生じている点における誤 差の二乗和を用いる (式 3 , 図 4).

$$
E\left(x_{i}\right)=\sum_{\boldsymbol{x}_{i} \in \text { inside }}\left(Q\left(\boldsymbol{x}_{i}\right)-r\right)^{2}+\sum_{\boldsymbol{x}_{\imath} \in \text { outside }}\left(Q\left(\boldsymbol{x}_{i}\right)+r\right)^{2} \rightarrow \min
$$

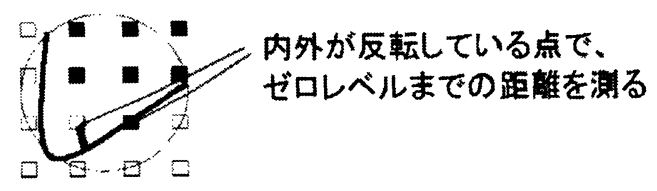

\section{図 4 誤差評価}

\section{3. 㓌関数曲面モデル生成アルゴリズム}

本小節では，入力である連続 2 值画像から，出力であ る陰関数曲面モデルを生成するためのアルゴリズムに ついて述べる.

まず連続 2 值画像からボクセルモデルを作成し, 前景 と背景の境界上の点を曲面近似に用いる球の巾心点候補 として抽出する. 以下, 抽出した点の集まりを巾心候補 点群, 巾心候補点群の一要素を巾心候補点と呼ぶ. 各中 心候補点には, 初期值として 0 を取る重みを設定する. SLIM 曲面では関数ごとに異なる大きさの球を必要とす るため, 関数の影響範囲を求めるにあたり 2 分法を用い る. 関数の影響範囲と近似関数を求めるために，まず巾 心候補点群から中心候補点 $p_{i}$ を無作為に選択し, $p_{i}$ を 巾心に大小 2 つ半径をもつ球を置く. 式 3 により求め られる半径 $r$ における近似関数の誤差の值を $E(r)$, パ ラメータとして与えた誤差の理想値を $E_{i d e a l}$ とした時,

$$
E\left(r_{S}\right)<E_{\text {ideal }}<E\left(r_{L}\right)
$$

となる 2 つの半径 $r_{S}, r_{L}$ を求める.

そして, 中心点 $p_{i}$, 半径 $r_{M}=\left(r_{S}+r_{L}\right) / 2$ の球の内部 の全点をサンプリングする．全サンプリング点を用い て，3．2. 節で述べた方法によって得られた連立方程式 を，最小二乗法を用いて解くことで $Q\left(\mathbf{x}_{\mathbf{i}}\right)$ の係数を求 める. $Q\left(\mathbf{x}_{\mathbf{i}}\right)$ を用いて式 3 に従い誤差 $E\left(r_{M}\right)$ を評価し， $E\left(r_{M I}\right)<E_{\text {idial }}$ であれば $r_{S}=r_{M I}, E\left(r_{M}\right)>=E_{\text {idial }}$ であれば $r_{L}=r_{S}$ として新たな $r_{S}, r_{L}$ を定める.

これを $r_{L}-r_{S}$ が䦨值以下となるまで繰り返し, 求め られた $r_{S}$ を関数の影響範囲である球の半径 $r_{i}$ と定め る.ここで誤差 $E\left(r_{M}\right)$ を理想誤差 $E_{i}$ に近づけるよう に $r_{M}$ を変化させながら関数の当てはめを繰り返し行う ことで, 精度を保ちつつデータ量を小さくしたモデルの 構成ができる．また近似関数の精度を抑えることで, 物 体表面のノイズの除去の効果が得られる.

半径 $r_{i}$ が求められたら, 点 $p_{i}$ との距離が $r_{i}$ 以下の巾 心候補点に対して, 半径 $r_{i}$ に比例し点 $p_{i}$ からの距離に 
反比例するような重み関数を用いて重みに加算を行う 重みが一定值を超えた点を中心候補点群から取り除く ことで，近似関数の無駄な重複を省くことができる．以 上の処理を，中心点候補がなくなるまで繰り返すことで 陰関数曲面モデルが作成される。

3. 4. 3 次元陰関数曲面モデルの可視化

可視化は，ポリゴン化手法の一つであるデュアルカン タリング法 [7] を用いる. 提案手法により作成したモデ ルでは, 物体が薄い箇所において, 陰関数が断裂する場 合がある。図 5(a) に例を示す。これは，関数の影響範 囲の球がそれぞれ半径を超えて乘離することに起因す る.レイキャスティング法などの陰関数を直接可視化す る手法の場合，断裂寸る箇所において物体が閉じていな い形状として可視化される. 本研究ではポリゴン化を行 うことにより，断裂のある陰関数を用い，閉じた形状を 表現する (図 5(b)).
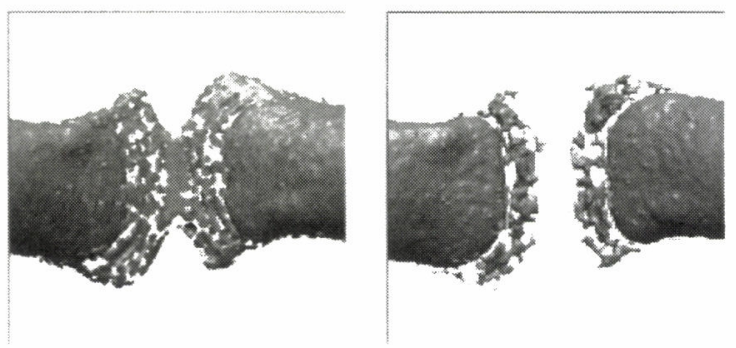

図 5 断裂箇所 (a) とそのポリゴン表現 (b)

4. 形状モデル生成の実験と考察

本節では，提案手法を用いて作成した陰関数曲面モデ ルを用い，可視化を行った結果を示す．また，提示した 画像から考えられる特徴について，考察を行う。

\section{1. 実験方法}

時系列連続 2 值画像から 4 次元の陰関数曲面を生成 する. 次に生成されたモデルの, 時間をパラメータとし て与えた際に得られる形状を表示して評価を行う。出力 画像は陰関数曲面を元にデュアルカンタリングを用いて ポリゴン化を行い，表示する.

実験に当たって使用した環境を以下に示す.

CPU: PentiumM $1.69 \mathrm{GHz}$

OS: WindowsXP

メモリ：1GB

コンパイラ: cygwin gec-3.4.3

\section{2. 実験結果}

本小節では, 入力データである時系列連続 2 值画像を 用いた 4 次元陰関数曲面モデルの生成実験結果につい て述べる.

\section{2. 1. 位相変化のある 4 次元形状}

図 6 に, 8 の字形状からトーラスへのモーフィング データを表す時系列連続 2 值画像の一部を示す．図 7 に 位相が変わる例題として，8の字形状からトーラスへの モーフィングデータを示す.この例題は, $t=[0,1]$ に おいて等間隔に 21 の連続 2 值画像のサンプルを作成し, それらを入力として生成した 4 次元陰関数曲面モデル の可視化結果である。一つの連続 2 值画像は, 縦横が $347 \times 347$ の 2 值画像 347 枚により構成される. 図 6 は 図 7 で示された陰関数曲面モデルの生成に用いられた 時系列連続 2 值画像の, $t=0$ における連続 2 值画像の $z=150$ から $z=179$ に相当する 2 值画像である.

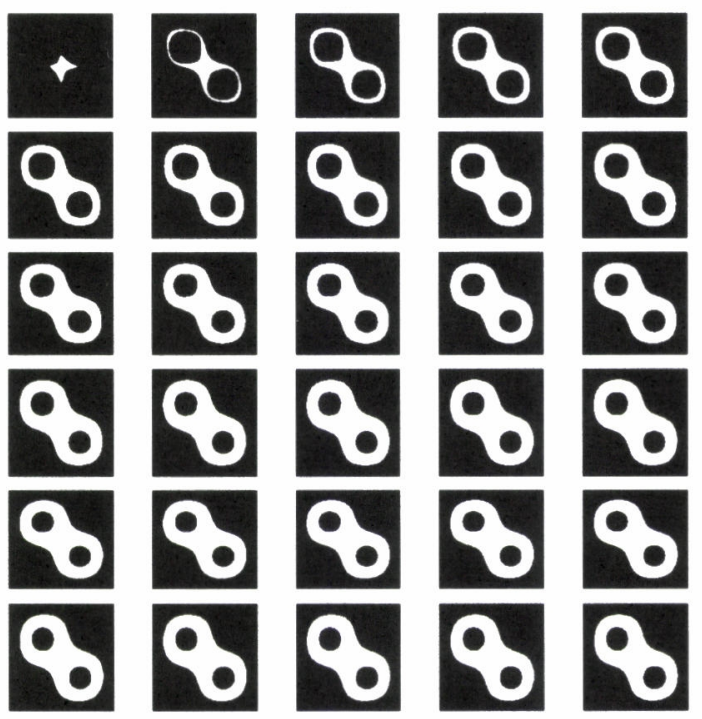

図 6 [例 1]8の字形状からトーラスへのモーフィングデータ の時系列連続 2 值画像の一部

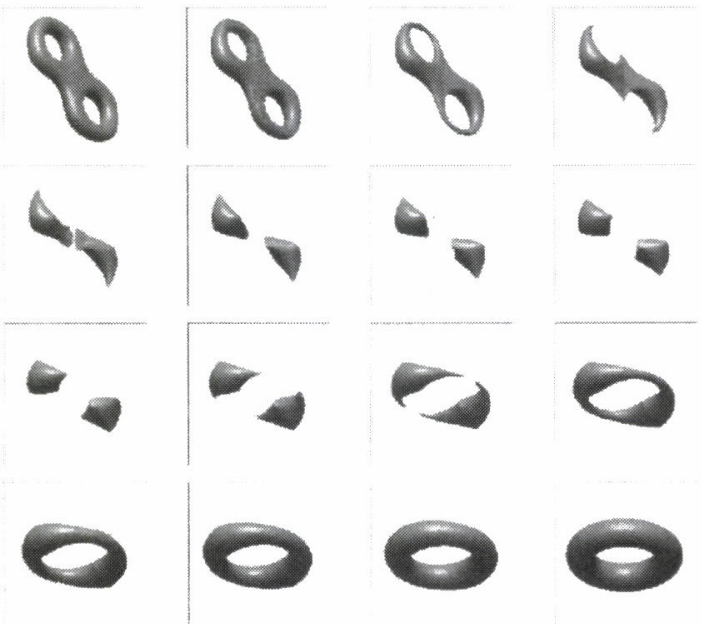

図 7 [例 1]8 の字形状からトーラスへの変化を示す 4 次元陰関数の出力画像 
図7からわかるように，位相の変化する形状も特別な 処理を必要とせず表現できることがわかる. 図 7 最上 図中央左では，形状の表面に著しい凹凸が確認できる。 これは単位時間当たりの形状の変化が大きいために, 形 状の変化を滑らかに表現する陰関数を当てはめることが 出来ず, 別の時間における表面を示す陰関数の残涬が, ノイズのように出現しているためと考えられる. 対策と しては, 単位時間当たりの形状の変化を小さくするため により時間方向の刻みが多い入力を用いる，あるいはパ ラメータとして与える誤差の理想值をより大きくする ことで一つ一つの近似関数の影響範囲を大きくするこ とが考えられる。しかし前者の対処法は入力データに依 存するため効果的な対処とは考えられず, 後者の対処法 の場合, 誤差の理想值を大きくすることで全体的に入力 データの再現性が低下寸ることが賏念される，入力デー 夕における時間当たりの変化が大きすぎる場合, この手 法では有効なモデリングができないと考えられる.

\section{2. 2. 分裂する球体}

図 8 に, 基礎的な位相の変化を含む形状変化である 球体の分裂を表現したモーフィングデータを示す。この 例題は, $t=[0,1]$ において等間隔に 100 の連続 2 值画 像のサンプルを作成し，それらを入力として生成した 4 次元陰関数曲面モデルの可視化結果である. 一つの連続 2 值画像は，縦横が $100 \times 100$ の 2 值画像 100 枚により 構成される。図 8 からわかるように，時間方向のサンブ リングを十分に行うことでノイズ，誤差の少ない出力を 得られることがわかる.

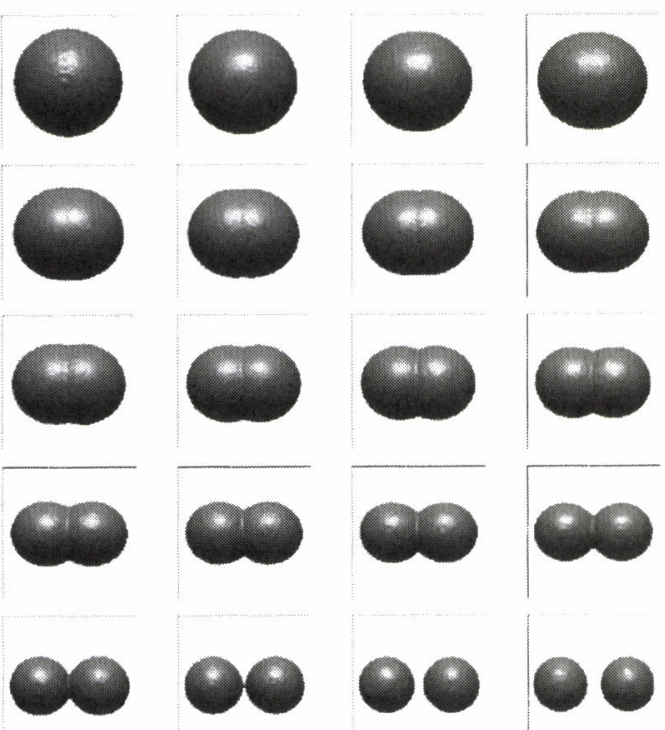

図 8 [例 2] 球の分裂を示す 4 次元陰関数の出力画像

\section{2. 3. ドラゴン形状の内部表現}

図 9 に，ドラゴン形状 (stanford Dragon) を元に作成 された連続 2 值画像の一部走示寸。図 10 に，等距離場 生成手法により，ドラゴン形状を元に作成された 11 の 連続 2 值画像を入力として生成した 4 次元陰関数曲面 モデルの可視化結果を示寸.一つの連続 2 值画像は, 縦 横が $512 \times 512$ の 2 值画像 233 枚により構成される. 図 9 は, 図 10 で示した陰関数曲面モデルの生成に用いら れた時系列連続 2 值画像の, $t=0$ における連続 2 值画 像の $z=70$ から $z=99$ に相当する 2 值画像である.

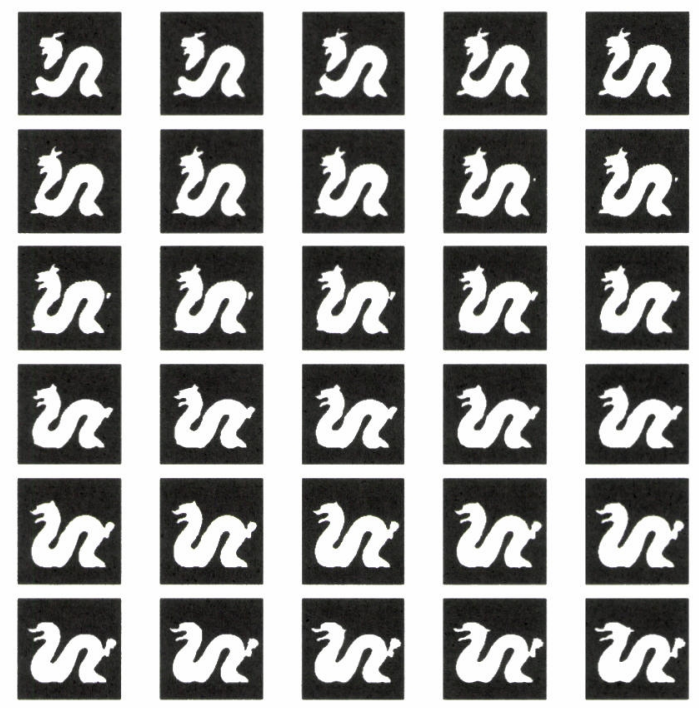

図 9 [例 3] ドラゴンの変形を示す時系列連続 2 值画像の一部
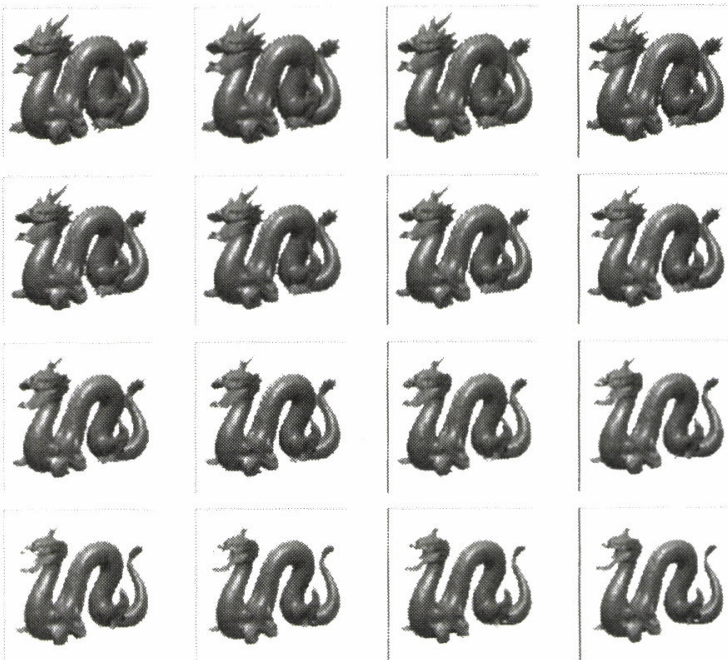

図 10 [例 3] ドラゴンの变形を示す 4 次元陰関数の出力画像

図10からわかるように，このドラゴンのモデルは入 カデータに拉ける単位時間当たりの形状の変化量が小 さいため, 人力の再現性の高い出力であることが確認で きる. また, $t=0$ (図 10 左上) 及び $t=1$ (図 10 右 
下）以外の出力結果より, 入力の連続 2 值画像が存在し ない時間における形状も生成が可能であることが確認 できる。しかし，図10下列胦左，下列胦右に，一 部孤立した領域に形状が生成されている。これは消失し つつある箇所の出力であると考えられる. 消失過程の箇 所を含む形状を元にモデルを生成する場合，こういった ノイズと考えられる出力が生まれる場合がある.陰関数 では,このようなノイズへの対処は難しく，除去が必要 であればポリゴン化時にノイズを描画しないような処 理が必要である.

表 1 に, 各実験例の陰関数曲面モデル生成処理の実行 時間, 中心候補点数, 近似曲面数を示寸. 例 1 は 8 の字 からトーラスへのモーフィングデータを元にしたモデリ ング, 例 2 は球の分裂を表すモーフィングデータを元に したモデリング, 例 3 は Stanford Dragon を元にしたモ デリングにおけるデータを示すものである. 中心候補点 数は, 入力の連続 2 值画像における前景と背景の境界 に相当する点の個数であり，前景の表面積に比例する. 近似曲面数は, 出力の 4 次元陰関数曲面モデルに含まれ る陰関数曲面の数である. 近似曲面数は, 中心候補点数 と, 関数による形状表現の困難さに応じて増加する.

\section{表 1 各実験例の实行時間とデータ}

\begin{tabular}{c|c|c|c}
\hline 実験例 & 処理時間 & 巾心候補点数 & 近似曲面数 \\
\hline \hline 例 1 & 76.92 分 & 2284790 & 113338 \\
例 2 & 18.72 分 & 2129526 & 69017 \\
例 3 & 119.73 分 & 5790727 & 78651 \\
\hline
\end{tabular}

\section{5. おわりに}

本論文では時系列を持つ連続断層画像によって表され た時間によって形状が変化する物体に 4 次元の陰関数曲 面を当てはめ, 物体の形状変化を表現できるモデル生成 手法を提案した。提案手法により，任意の時間における 3 次元形状を表現することが可能なモデルを構築するこ とができた.

\section{参考文献}

[1] Y. Ohtake, A. Belyaev and M. Alexa: Sparse Low-degree Implicit Surfaces with Applications to High Quality Rendering, Feature Extraction, and Smoothing. In Eurographics Symposium on Geometry Processing(2005)

[2] Y. Ohtake, A. Belyaev, M. Alexa, G. Turk and H.P. Seidel: Multi-level Partition of Unity Implicits. In ACM SIGGRAPH(2003)
[3] J. C. Carr, R. K. Beatson, J.B. Cherrie, T. J. Mitchell, W. R. Fright, B. C. McCallum and T. R. Evans: Reconstruction and Representation of 3D Objects with Radial Basis Functions. In ACM SIGGRAPH(2001)

[4] T. Kanai, Y. Ohtake, H. Kawata, K. Kase: GPU-based Rendering of Sparse Low-degree IMplicit Surfaces. In 4th International Conference on Computer Graphics and Interactive Techniques in Australasia and the Southeast Asia (GRAPHITE 2006)

[5] W. E. Lorensen and H. E. Cline A high resolution 3D surface construction algorithm. In ACM SIGGRAPH(1987)

[6] L. P. Kobbelt, M. Botsch, U. Schwanecke and H.-P. Seidel: Feature sensitive surface extraction from volume data. In ACM SIGGRAPH(2001)

[7] T. Ju, F. Losasso, S. Schaefer and J. Warren: Dual Contouring of Hermite Data. In ACM SIGGRAPH(2002)

\section{著者紹介}

渡部広志：埼玉大学情報システム工学科 近藤 邦雄 : 埼玉大学理工学研究科

大竹豊：理化学研究所 VCAD モデリングチーム 金井 崇：東京大学大学院総合文化研究科 道川隆士：東京大学先端科学技術研究センター 